\title{
Receptors for recombinant feline interferon- $\omega$ in hemocytes of the Japanese pearl oyster Pinctada fucata martensii
}

\author{
Teruo Miyazaki*, Tomohito Taniguchi, Jinto Hirayama, Naoki Nozawa \\ Faculty of Bioresources, Mie University, 1515 Kamihama, Tsu, Mie 514-8507, Japan
}

\begin{abstract}
In a previous study we determined that administration of recombinant feline interferon$\omega(\mathrm{rFeIFN}-\omega)$ could protect Japanese pearl oysters Pinctada fucata martensii from akoya-virus infection. Our results suggested that $\mathrm{rFeIFN}-\omega$ enhanced the potential of agranulocytes to phagocytize necrotic cells and to produce collagen fibers that repair the lesions caused by the akoya-virus. In the present study, using an indirect immunofluorescence technique with an anti-rFeIFN- $\omega$ rabbit serum, we examined whether hemocytes bear receptors that bind $\mathrm{rFeIFN}-\omega$. rFeIFN- $\omega$ receptors were present on agranulocytes and bound rFeIFN- $\omega$, and appeared as green fluorescent spots in the cytoplasm under a fluorescent microscope. Around $56 \%$ of agranulocytes in Japanese pearl oysters bore the $\mathrm{rFeIFN}-\omega$ receptors.
\end{abstract}

KEY WORDS: Japanese pearl oyster $\cdot$ Agranulocytes $\cdot$ rFeIFN- $\omega$ receptor $\cdot$ Akoya-virus

\section{INTRODUCTION}

In a previous study, we found that administration of recombinant feline interferon- $\omega(\mathrm{rFeIFN}-\omega)$ was effective in preventing mortality in Japanese pearl oysters (akoya oyster) Pinctada fucata martensii due to infection by the akoya-virus which has caused mass mortalities in recent years in western Japan (Miyazaki et al. 1999, 2000). Akoya oysters injected with akoya-virus and subsequently treated by injections with rFeIFN- $\omega$ survived and displayed the regenerating characteristics of necrotic lesions associated with akoya-virus infection: many agranulocytes phagocytized necrotic cells and synthesized collagen fibrils which produced fibrous tissues to replace the necrotic lesions in the adductor, pallial and peduncle musculature as well as in the myocardium. It has been reported that in naturally healing wounds in akoya oysters agranulocytes performed phagocytosis and production of fibrous materials outside the cells (Suzuki et al. 1991, Suzuki \&

*E-mail: miyazaki @bio.mie-u.ac.jp
Awaji 1995). This suggests that rFeIFN- $\omega$ enhances the potential of agranulocytes to phagocytize necrotic cells and to produce collagen fibers that repair the lesions caused by the akoya-virus. Since no akoya-virus was reisolated from survivors, these enhanced agranulocytes must have phagocytized the intracellular viral particles whilst phagocytizing cellular debris in the lesions. In the present study, we investigated whether hemocytes of akoya oysters bear rFeIFN- $\omega$ receptors, since in order to enhance the potential of agranulocytes the agranulocytes must possess receptors that react with rFeIFN- $\omega$. We examined the rFeIFN- $\omega$ receptors of agranulocytes by an indirect immunofluorescence technique using anti-rFeIFN- $\omega$ rabbit serum.

\section{MATERIALS AND METHODS}

Preparation of anti-rFeIFN- $\omega$ rabbit serum. Prior to injection of rFeIFN- $\omega, 10 \mathrm{ml}$ of blood was removed from the ear artery of a white rabbit to prepare normal serum. The serum was inactivated at $56^{\circ} \mathrm{C}$ for $30 \mathrm{~min}$, filtered $(450 \mathrm{~nm})$ and stored at $-80^{\circ} \mathrm{C}$. An inoculum of a 
mixture of a rFeIFN- $\omega$ solution and Freund's adjuvant (Wako) $(1: 1 \mathrm{v} / \mathrm{v})$ was injected under the dermis at several points on the rabbit's back. On each day that the rabbit was injected, it was given a total of $500 \mu \mathrm{g}$ rFeIFN- $\omega$. The rabbit received booster injections at intervals of $3 \mathrm{wk}$. One week after the third booster injection, $10 \mathrm{ml}$ of blood was removed. The titer of antirFeIFN- $\omega$ antibody in the serum was examined by the dot-blot method (Ohmi et al. 1995) and was found to be high, although the actual value was not determined. Therefore, 2 wk after the fourth booster injection, a large amount of blood $(50 \mathrm{ml})$ was removed from the ear artery. The anti-rFeIFN- $\omega$ rabbit serum was prepared using the routine protocol for preparing an antipeptide antibody (Ohmi et al. 1995).

Preparation of hemocytes from akoya oysters. Healthy akoya oysters were collected in December 2000 from Oita, western Japan, a location that has not yet experienced mass mortality due to akoya-virus infection. The hemolymph was removed from the adductor muscle with a $1 \mathrm{ml}$ syringe and was transferred to a glass tube placed in crushed ice. The hemolymph was centrifuged at $1200 \times g$ for $5 \mathrm{~min}$. The supernatant was removed and the hemocyte pellet was suspended in a $5 \mathrm{ml}$ MMBSS (marine molluscan balance salt solution; Machii \& Wada 1989). The hemocyte suspension was centrifuged and the cell pellet was rinsed in $5 \mathrm{ml}$ MMBSS. The cell suspension was centrifuged again and the cell pellet was suspended in 2 ml SM199 (Supplement Medium 199), a medium used for the long-term culture of molluscan cells (Machii \& Wada 1989). This cell suspension was divided into 2 portions of $1 \mathrm{ml}$ each.

In an attempt to induce a reaction of $\mathrm{rFeIFN}-\omega$ with the hemocytes receptors, a solution of rFeIFN- $\omega$ (Toray) was added to a final concentration of 0.01 mega unit (MU) $\mathrm{ml}^{-1}$ and allowed to stand for $1 \mathrm{~h}$ at $25^{\circ} \mathrm{C}$. The cell suspension was then rinsed twice in $2 \mathrm{ml}$ MMBSS. After the second centrifugation, the cell pellet was resuspended in $1 \mathrm{ml}$ MMBSS, 1 or 2 drops of the cell suspension were mounted on a glass slide, and this was air-dried.

For use as a blank control (no rFeIFN- $\omega$ treatment), 1 or 2 drops of cell suspension from the same oysters were mounted on a glass slide and air-dried.

A phosphate-buffered solution (PBS) containing 5\% calf serum albumin (Sigma) was mounted on the cellsmeared glass slides for 30 min inside a wet-box in order to block the hemocytes. These slides were rinsed twice with PBS (-) and air-dried. Cell sample smears were prepared from 10 pearl oysters.

Indirect immunofluorescence technique. In an attempt to bind the anti-rFeIFN- $\omega$ antibody with the rFeIFN- $\omega$ that had been bound to the rFeIFN- $\omega$ receptors of the hemocytes, PBS (-) containing $5 \%$ of anti-
rFeIFN- $\omega$ rabbit serum was mounted on cell-smeared glass slides for $1 \mathrm{~h}$ at $37^{\circ} \mathrm{C}$ inside a wet-box. The slides were rinsed 3 times with PBS $(-)$ and were then mounted with PBS (-) containing $1.5 \%$ anti-rabbit-Ig G goat serum combining FITC (Serotec) for $1 \mathrm{~h}$ at $37^{\circ} \mathrm{C}$ inside a dark wet-box. They were again rinsed 3 times with PBS (-) and mounted with $50 \%$ glycerine PBS (-) $(\mathrm{v} / \mathrm{v})$. For the cell count of rFeIFN- $\omega$ receptor-positive hemocytes, 2 or 3 slides were used. We also established a negative control, whereby 2 glass slides bearing cell smears were mounted with PBS (-) containing $5 \%$ of a normal rabbit serum and were processed in the same way as for the immunofluorescence tests. Two slides containing hemocytes that did not react with $\mathrm{rFeIFN}-\omega$ in the blank control were processed in the same way, using the anti-rFeIFN- $\omega$ antibody for immunofluorescence tests.

These slides were observed through a fluorescence microscope under G excitation.

\section{RESULTS}

We chose to observe agranulocytes because they are involved in the repair of necrotic lesions associated with akoya-virus in the musculature (Miyazaki et al. 2000). The granulocytes contained granules that autofluoresced orange. Since they comprised only a small proportion of the hemocyte count, the granulocytes were not counted in this study. Agranulocytes with green-fluorescing spots in the cytoplasm were considered to bear rFeIFN- $\omega$ receptors (Fig. 1). The number of fluorescent spots varied from cell to cell. Agranulocytes bearing $\mathrm{rFeIFN}-\omega$ receptors ( $\mathrm{r}$ +agranulocytes) were counted using smear samples from 10 pearl oysters, and comprised 50.5 to $70.6 \%$ of the total cell count (Table 1). On the smeared slides, $56.3 \%$ of a total of 712 cells were r+agranulocytes. Control hemocytes

Table 1. Pinctada fucata martensii. Number of r+agranulocytes (r+agr.) in Japanese pearl oysters and percentage they comprised of the total cell count

\begin{tabular}{|lcc|}
\hline Oyster no. & No. r+agr./total & \% r+agr. \\
\hline 1 & $15 / 22$ & 68.2 \\
2 & $46 / 91$ & 50.5 \\
3 & $17 / 27$ & 63.0 \\
4 & $22 / 38$ & 57.9 \\
5 & $101 / 177$ & 57.1 \\
6 & $32 / 48$ & 66.7 \\
7 & $38 / 68$ & 55.9 \\
8 & $54 / 106$ & 50.9 \\
9 & $24 / 34$ & 70.6 \\
10 & $52 / 97$ & 53.6 \\
Total & $401 / 712$ & 56.3 \\
\hline
\end{tabular}



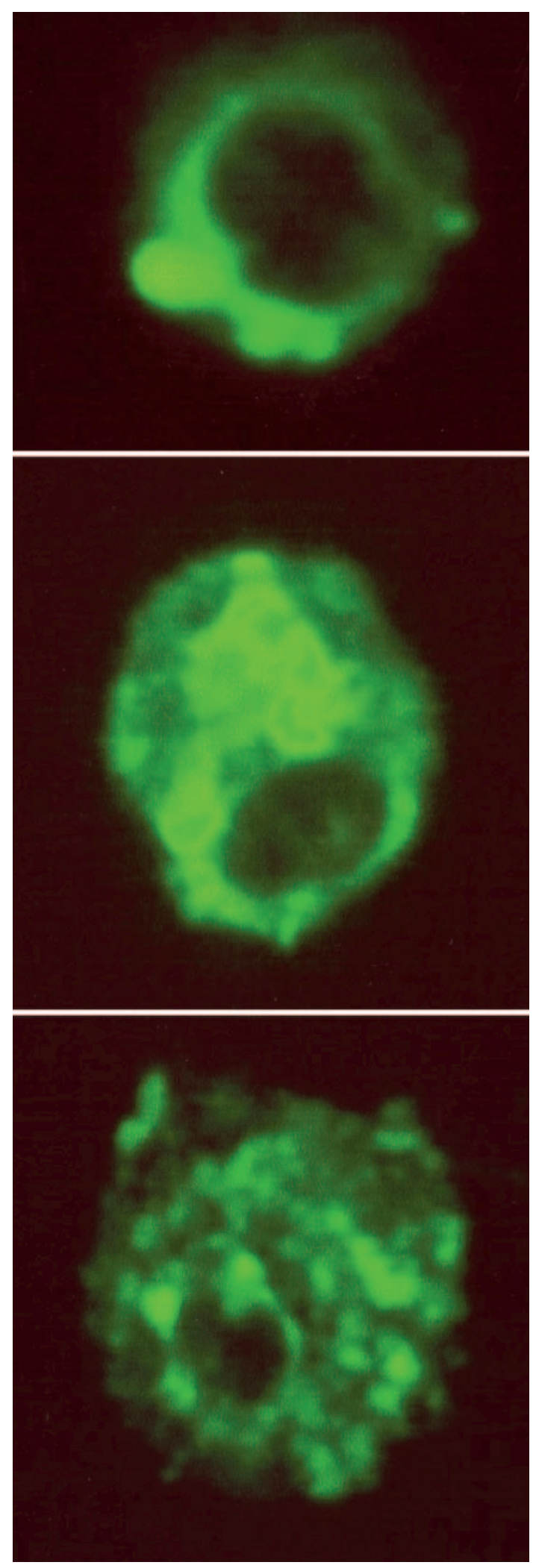

Fig. 1. Pinctada fucata martensii. Agranulocytes bearing rFeIFN- $\omega$ receptors with green-fluorescing spots in the cytoplasm that either did not react with rFeIFN- $\omega$ (blank control) or that were treated with normal rabbit serum instead of an anti-rFeIFN- $\omega$ rabbit serum (negative control) did not display any sign of fluorescence of the agranulocytes.

\section{DISCUSSION}

It is surprising that hemocytes of akoya oysters possess receptors for binding the $\mathrm{rFeIFN}-\omega$ of mammalian IFNs. In the akoya oysters we examined, almost $56 \%$ of the agranulocytes bore $\mathrm{rFeIFN}-\omega$ receptors. We have previously shown that $\mathrm{rFeIFN- \omega}$ administration is markedly effective in treating akoya-virus infection in akoya oysters (Miyazaki et al. 2000). The activity of r+agranulocytes appears to be enhanced when rFeIFN- $\omega$ reacted with their $r F e I F N-\omega$ receptors. Treated r+agranulocytes performed active phagocytosis of necrotized cells and produced collagen fibers to repair necrotic lesions caused by akoya-virus infection. Thus, rFeIFN- $\omega$ administration is effective in repairing necrotic lesions and preventing mortality in akoyavirus infected oysters (Miyazaki et al. 2000). In previous studies, the process of natural wound-healing has been examined in akoya oysters (Suzuki et al. 1991, Suzuki \& Awaji 1995), The Pacific oyster Crassostrea gigas (DesVoigne \& Sparks 1968, Ruddell 1971) and the freshwater mussel Andonta oregonensis (Pauley \& Heaton 1969). In akoya oysters, agranulocytes phagocytize necrotic cells and produce collagen fibrils at the wound site. The manner of collagen fibril synthesis of agranulocytes differs between naturally healing wounds of normal akoya oysters and those of akoyavirus-infected oysters that have been treated with rFeIFN- $\omega$. Agranulocytes of normal akoya oysters produce a collagen matrix outside the cells in a naturally healing wound and also in vitro cell culture (Suzuki et al. 1991, Suzuki \& Funakoshi 1992, Suzuki \& Awaji 1995). Agranulocytes treated with rFeIFN- $\omega$ synthesize numerous thin collagen fibrils within the cytoplasm at the site of the lesion, while in untreated akoya oysters with akoya-virus infection, myofibrocyte-like cells synthesize collagen fibers within the cytoplasm in the naturally healing lesions (Miyazaki et al. 2000). Thus, agranulocytes treated with rFeIFN- $\omega$ display distinctive characteristics when they actively repair akoyavirus-associated lesions.

\section{LITERATURE CITED}

DesVoigne DM, Sparks AK (1968) The process of wound healing in the Pacific oyster, Crassostrea gigas. J Invertebr Pathol 12:53-65

Machii A, Wada K T (1989) Some marine invertebrates tis- 
sue culture. In: Mitsuhashi J (ed) Invertebrate cell system application, Vol II. CRC Press, Boca Raton, FL, p 225-233

Miyazaki T, Goto K, Kobayqashi T, Kageyama T, Miyata M (1999) Mass mortalities associated with a virus disease in Japanese pearl oysters Pinctada fucata martensii. Dis Aquat Org 37:1-12

Miyazaki T, Nozawa N, Koboyashi T (2000) Clinical trial results on the use of a recombinant feline interferon- $\omega$ to protect Japanese pearl oysters Pinctada fucata martensii from akoya-virus infection. Dis Aquat Org 43:15-26

Ohmi SI, Tsujimura K, Inagaki M (1995) Experimental protocol for a preparation of anti-peptide antibody. Shujun-sha, Tokyo (in Japanese)

Pauley GB, Heaton LH (1969) Experimental wound repair in

Editorial responsibility: Albert Sparks,

Seattle, Washington, USA the freshwater mussel Anodonta oregonensis. J Invertebr Pathol 13:241-249

Ruddell CL (1971) The fine structure of oyster agranular amebocytes from regenerating mantle wounds in the Pacific oyster, Crassostrea gigas. J Invertebr Pathol 18:260-268

Suzuki T, Awaji M (1995) Wound healing. In: Mori K, Kamitani $\mathrm{H}$ (eds) Defence mechanisms of aquatic animals. Koseisha-Koseikaku, Tokyo, p 83-95 (in Japanese)

Suzuki T, Funakoshi S (1992) Isolation of a fibronectin-like molecule from a marine bivalve, Pinctada fucata, and its secretion by amebocytes. Zool Sci (Tokyo) 9:541-550

Suzuki T, Yoshinaka R. Mizuta S, Funakoshi S, Wada K (1991) Extracellular matrix formation by amebocytes during epithelial regeneration in the pearl oysters Pinctada fucata. Cell Tissue Res 266:75-82

Submitted: March 15, 2001; Accepted: January 28, 2002 Proofs received from author(s): August 5, 2002 